\title{
BMJ Open Risk factors for opioid-induced respiratory depression in surgical patients: a systematic review and meta- analyses
}

Kapil Gupta, ${ }^{1}$ Mahesh Nagappa, ${ }^{2}$ Arun Prasad, ${ }^{3}$ Lusine Abrahamyan, ${ }^{4}$ Jean Wong, ${ }^{3}$ Toby N Weingarten, ${ }^{5}$ Frances Chung ${ }^{3}$

To cite: Gupta K, Nagappa M, Prasad A, et al. Risk factors for opioid-induced respiratory depression in surgical patients: a systematic review and meta-analyses. BMJ Open 2018;8:e024086. doi:10.1136/ bmjopen-2018-024086

- Prepublication history and additional material for this paper are available online. To view these files, please visit the journal online (http://dx.doi. org/10.1136/bmjopen-2018024086).

$\mathrm{KG}$ and $\mathrm{MN}$ shared first authorship

Received 9 May 2018 Revised 9 August 2018 Accepted 2 October 2018

Check for updates

(C) Author(s) (or their employer(s)) 2018. Re-use permitted under CC BY-NC. No commercial re-use. See rights and permissions. Published by BMJ.

For numbered affiliations see end of article.

Correspondence to

Dr Frances Chung;

Frances.Chung@uhn.ca

\section{ABSTRACT}

Objective This systematic review and meta-analysis aim to evaluate the risk factors associated with postoperative opioid-induced respiratory depression (OIRD).

Design Systematic review and meta-analysis.

Data sources PubMed-MEDLINE, MEDLINE in-process, EMBASE, Cochrane Central Register of Controlled Trials, Cochrane Database of Systematic Reviews, PubMed and Clinicaltrials.gov (January 1946 to November 2017).

Eligibility criteria The inclusion criteria were: (1) adult patients 18 years or older who were administered opioids after surgery and developed postoperative OIRD (OIRD group); (2) all studies which reported both OIRD events and associated risk factors; (3) all studies with reported data for each risk factor on patients with no OIRD (control group) and (4) published articles in English language.

Data analysis We used a random effects inverse variance analysis to evaluate the existing evidence of risk factors associated with OIRD. Newcastle-Ottawa scale scoring system was used to assess quality of study.

Results Twelve observational studies were included from 8690 citations. The incidence of postoperative OIRD was 5.0 cases per 1000 anaesthetics administered $(95 \% \mathrm{Cl}$ : 4.8 to 5.1; total patients: 841 424; OIRD: 4194). Eightyfive per cent of OIRD occurred within the first 24 hours postoperatively. Increased risk for OIRD was associated with pre-existing cardiac disease (OIRD vs control: $42.8 \%$ vs $29.6 \%$; OR: $1.7 ; 95 \% \mathrm{Cl}: 1.2$ to $2.5 ; \mathrm{I}^{2}: 0 \% ; \mathrm{p}<0.002$ ), pulmonary disease (OIRD vs control: $17.8 \%$ vs $10.3 \%$; OR 2.2; $95 \% \mathrm{Cl}: 1.3$ to $\left.3.6 ; \mathrm{I}^{2}: 0 \% ; \mathrm{p}<0.001\right)$ and obstructive sleep apnoea (OIRD vs control: $17.9 \%$ vs $16.5 \%$; OR: 1.4 ; $95 \% \mathrm{Cl}: 1.2$ to $\left.1.7 ; \mathrm{I}^{2}: 31 \% ; \mathrm{p}=0.0003\right)$. The morphine equivalent daily dose of the postoperative opioids was higher in the OIRD group than in the control; $(24.7 \pm 14 \mathrm{mg}$ vs $18.9 \pm 13.0 \mathrm{mg}$; mean difference: $2.8 ; 95 \% \mathrm{Cl}: 0.4$ to $\left.5.3 ; l^{2}: 98 \% ; p=0.02\right)$. There was no significant association between OIRD and age, gender, body mass index or American Society of Anesthesiologists physical status.

Conclusion Patients with cardiac, respiratory disease and/or obstructive sleep apnoea were at increased risk for OIRD. Patients with postoperative OIRD received higher doses of morphine equivalent daily dose.

\section{Strengths and limitations of this study}

- This is the first meta-analysis to provide a comprehensive, up-to-date analysis of the available evidence on the risk factors associated with opioid-induced respiratory depression in in the postoperative period.

- This is the first meta-analysis which addresses 'whom to monitor' (cardiac, respiratory disease and/ or obstructive sleep apnoea) and 'when to monitor' (up to 24 hours) for postoperative opioid-induced respiratory depression.

- This meta-analysis has limitations inherent to observational studies, as quality and completeness of medical records would have adversely influenced the results.

- There could be a publication bias, as we searched only articles in English language.

\section{INTRODUCTION}

Opioids are the cornerstone therapy for the management of moderate to severe postoperative pain, but they have numerous adverse effects, the most serious being opioid-induced respiratory depression (OIRD). ${ }^{1}$ Postoperative OIRD increases perioperative cost and hospital length of stay (LOS) and may result in permanent morbidity and mortality. ${ }^{2}$ The major cause of opioid-related death is OIRD, which leads to hypoxia and hypercapnia, further accentuating the vicious cycle, finally causing cardiorespiratory arrest.

Challenges exist in studying this important postoperative complication. First, the definitions of OIRD vary. This results in a widely varied reported incidence ranging from $0.04 \%$ to $0.5 \%$ when naloxone utilisation is used as a surrogate to $23 \%-41 \%$ when OIRD is assessed by hypoxaemia or bradypnoea. ${ }^{3-14}$ Second, when OIRD is restricted to a narrow definition (naloxone administration), its incidence is too low for evaluation with standard 
prospective randomised control trials. Over the past few years, several observational studies have been published that examined postoperative OIRD. ${ }^{3-14}$

A better understanding of risk factors predisposing to OIRD could potentially lead to better prevention strategies. The primary objective of this systematic review and meta-analysis (SRMA) was to evaluate the published literature to identify the potential associations between patient and procedural characteristics and postoperative OIRD. Knowledge of risk factors of OIRD will enable the healthcare providers to take appropriate precautions, plan risk mitigation, titrate the dose of opioids and use enhanced monitoring in high-risk patients.

\section{METHODS}

The reporting of this study followed the Preferred Reporting Items for Systematic Reviews and Meta-Analyses guidelines. ${ }^{15}$

\section{Patient and public involvement}

This study is a SRMA and does not involve the patients and or public.

\section{Search strategy}

Literature sources

The literature search was performed with the help of an expert research librarian familiar with the content area. The following databases were searched using the MeSH keywords according to the predesigned protocol (online supplementary file S1): PubMed-MEDLINE, MEDLINE in-process, EMBASE and EMBASE Classic, Cochrane Central Register of Controlled Trials, Cochrane Database of Systematic Reviews, PubMed and ClinicalTrials.Gov. Initial search was first conducted from January 1946 to November 2016. Full search strategy (including MeSH terms) is shown in online supplementary file S2. A repeat search was performed in November 2017 just before finalising our data for statistical analyses to find any new studies on OIRD.

\section{Inclusion and exclusion criteria}

This systematic review included adult surgical patients ( $\geq 18$ years), who were administered opioids during their hospital stay after surgery and had postoperative OIRD (OIRD group). We included observational studies that reported both OIRD events and risk factors that predicted or were associated with the occurrence of OIRD. Studies which reported data for each risk factor in the control group were included in the meta-analysis. Case reports, editorials and letters to journals were excluded. Only published articles in the English language were selected.

\section{Outcome definition}

For this SRMA, OIRD was defined by including the definitions of OIRD from all 12 studies, ${ }^{3-14}$ that is, naloxone administration for reversal of respiratory depression (respiratory rate $<8 / \mathrm{min}$ and/or oxygen saturation $<90 \%$ and / or apnoea $\geq 10$ s), excessive sedation or upper airway obstruction.

\section{Study selection process}

Studies were selected independently by two reviewers (KG, MN/AP), who first screened the titles and abstracts to determine whether the studies met the eligibility criteria. Full text copies of articles that were deemed to be potentially relevant were retrieved. Any disagreements were resolved by consulting the senior author (FC). Duplicate publications were excluded. A citation search by manual review of references from primary or review articles was also performed.

\section{Data extraction}

A data extraction form was designed and piloted by one of the authors (KG). All data were extracted independently by two reviewers ( $\mathrm{KG}$ and $\mathrm{MN}$ ). If a consensus could not be reached, the senior author was consulted (FC) to make the final decision. The following information was collected from each study: author, year of publication, country of origin, study design, total sample size, number of patients with OIRD, location and time of OIRD ( $<12$ hours and $<24$ hours), type of surgery and anaesthesia, medical comorbidities, outcomes reported and risk factors for OIRD. For the purpose of meta-analysis, data collection to evaluate the risk factors for OIRD were divided into the following categories: (1) demographic risk factors: age, gender, body mass index (BMI) and American Society of Anesthesiologists (ASA) physical status; (2) medical comorbidities: cardiac disease, pulmonary disease, obstructive sleep apnoea (OSA), diabetes mellitus (DM), renal disease and other; (3) type of surgery (general, orthopaedics, thoracic, urology, head and neck, transplant and neurosurgeries); (4) opioid-related risk factors: types, doses (morphine equivalent daily dose (MEDD)), routes of delivery (patient-controlled (PCA), epidural, intravenous, oral, nurse-administered analgesia) and concomitant administration of sedatives; (5) types of anaesthesia (general anaesthesia, neuraxial anaesthesia and combined general and neuraxial anaesthesia) and (6) LOS. Two investigators (KG,MN) evaluated study quality in accordance with the Meta-analysis Of Observational Studies in Epidemiology guidelines and Newcastle-Ottawa scale. ${ }^{1617}$

\section{Statistical analysis}

Meta-analyses were performed to identify the potential risk factors for developing OIRD across demographics, medical comorbidities, types of surgery and anaesthesia and opioid-related characteristics. A risk factor was considered for meta-analysis if it was evaluated, and data were available in at least two studies. For dichotomous risk factors (eg, gender, comorbidities), OR comparing each risk factor with $95 \% \mathrm{CI}$, was calculated from the number of events in each group and total number in each group. For continuous risk factors (eg, age, BMI, MEDD and LOS), the weighted difference in means between groups 
was calculated from the mean and SD in each group. The inverse variance method was used to pool effect estimates for both dichotomous and continuous risk factors. The effect sizes were pooled using random effects models. For statistically significant risk factors, influential analysis was performed. The analysis was conducted using the Review Manager software (RevMan, V.5.3). $\mathrm{P}<0.05$ was considered as statistically significant. Heterogeneity between studies was assessed using the $\mathrm{I}^{2}$ statistic. Heterogeneity was explored by excluding each of the studies and estimating the contribution of trials towards heterogeneity.
A symmetrical inverted funnel plot was considered as the absence of publication bias. This was cross-checked by Egger's regression test.

\section{RESULTS}

Our initial search yielded 8690 citations (figure 1). After deduplication, 6984 records were screened by titles and abstracts, and 125 articles were extracted for full-text reviews. Twelve observational studies met the inclusion criteria for the systematic review. ${ }^{3-14}$ The systematic

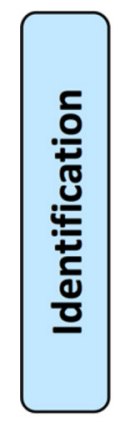

Articles identified through database $\operatorname{search}(n=8683)$
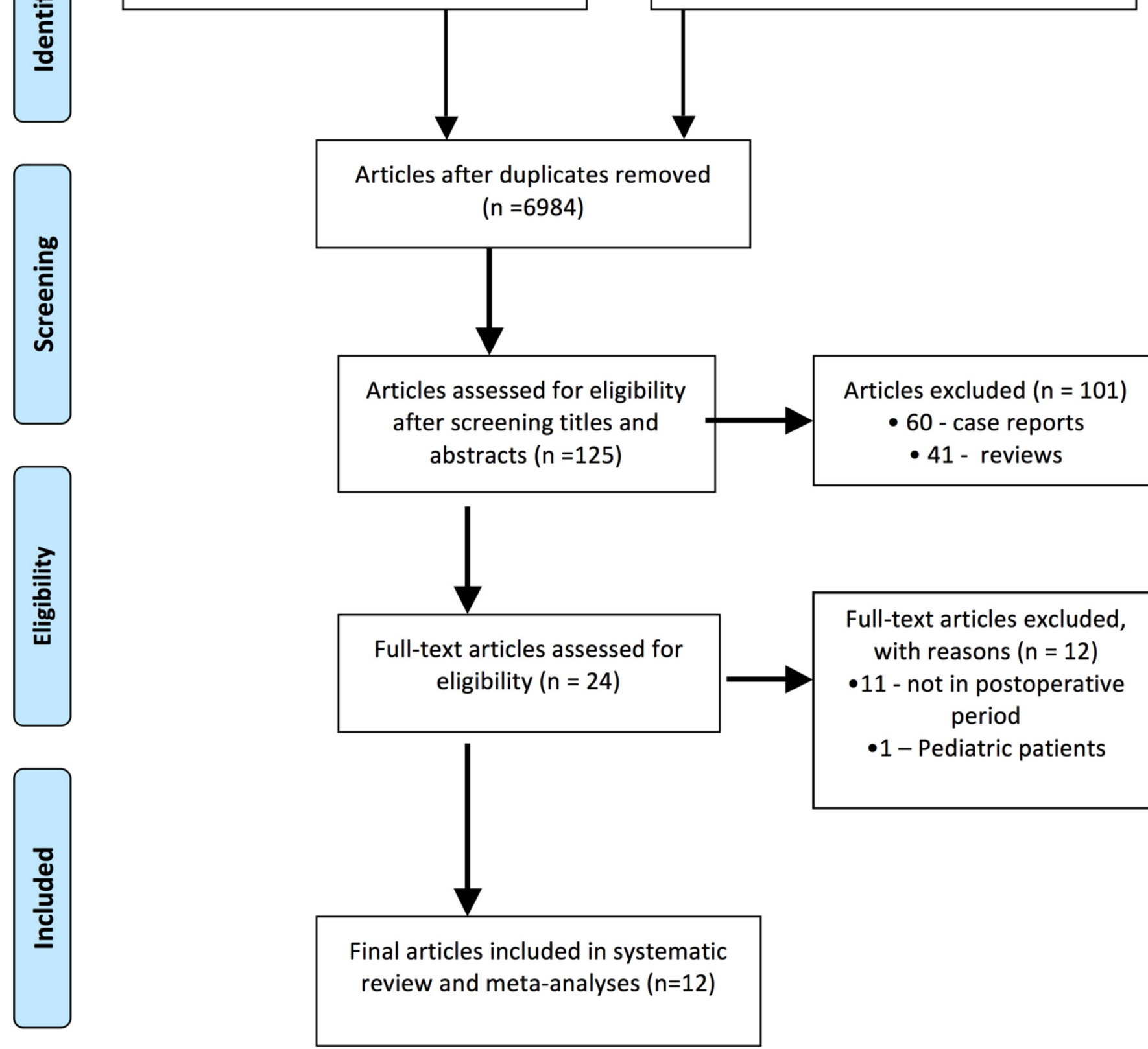

Full-text articles excluded, with reasons $(n=12)$

-11 - not in postoperative period

$\bullet 1$ - Pediatric patients

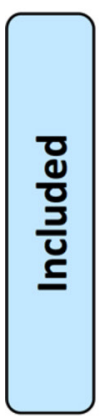

Final articles included in systematic review and meta-analyses $(n=12)$

Figure 1 Flow diagram of search strategy used for systematic review and meta-analysis. 
Table 1 Demographic data of OIRD

\begin{tabular}{|c|c|c|c|c|c|c|c|}
\hline \multirow{2}{*}{ Study ID et al (country) } & \multirow{2}{*}{$\begin{array}{l}\text { Total } \\
\text { patients }(\mathrm{n})\end{array}$} & \multirow{2}{*}{$\begin{array}{l}\text { Total OIRD } \\
\text { n (\%) }\end{array}$} & \multirow{2}{*}{$\begin{array}{l}\text { OIRD within } 12 \\
\text { hours }-\mathrm{n}(\%)\end{array}$} & \multirow{2}{*}{$\begin{array}{l}\text { OIRD within } 24 \\
\text { hours }-\mathrm{n}(\%)\end{array}$} & \multicolumn{3}{|c|}{ OIRD group } \\
\hline & & & & & Age (year) & Women(n) & BMI $\left(\mathrm{kg} / \mathrm{m}^{2}\right)$ \\
\hline $\begin{array}{l}\text { Etches }^{6} \\
\text { (Canada) }\end{array}$ & 1600 & $11(0.69)$ & $6(55 \%)$ & $9(82)$ & $55 \pm 16$ & 3 & NA \\
\hline $\begin{array}{l}\text { Gordon and Pellino }{ }^{14} \\
\text { (USA) }\end{array}$ & 10511 & $44(0.53)$ & NA & $25(57)$ & $60 \pm 16$ & 36 & NA \\
\hline $\begin{array}{l}\text { Shapiro et } a l^{13} \\
\text { (Israel) }\end{array}$ & 1524 & $18(1.18)$ & NA & NA & $51 \pm 24$ & 14 & $25.4 \pm 6.5$ \\
\hline $\begin{array}{l}\text { Taylor et a }{ }^{5} \\
\text { (USA) }\end{array}$ & - & 62 & $35(56)$ & $48(77)$ & $68 \pm 16$ & 38 & NA \\
\hline $\begin{array}{l}\text { Overdyk et al }{ }^{12} \\
\text { (USA) }\end{array}$ & 178 & $73(41)$ & NA & NA & NA & NA & NA \\
\hline $\begin{array}{l}\text { Ramachandran et a }\left.\right|^{11} \\
\text { (USA) }\end{array}$ & 85650 & $32(0.04)$ & NA & $27(84)$ & $52 \pm 17$ & 18 & $32.5 \pm 9.2$ \\
\hline $\begin{array}{l}\text { Khelemsky et al }{ }^{9} \\
\text { (USA) }\end{array}$ & 442699 & $433(0.10)$ & NA & NA & $60 \pm 16$ & 260 & $27 \pm 7$ \\
\hline $\begin{array}{l}\text { Lee et a }\left.\right|^{10} \\
\text { (USA) }\end{array}$ & 9799 claims & 92 claims & NA & $81(88)$ & $50 \pm 18$ & 52 & NA \\
\hline $\begin{array}{l}\text { Weingarten et al }{ }^{8} \\
\text { (USA) }\end{array}$ & 84533 & $134(0.16)$ & $78(58)$ & $110(82)$ & $65 \pm 15$ & 78 & $28.9 \pm 6.8$ \\
\hline $\begin{array}{l}\text { Weingarten et al }{ }^{7} \\
\text { (USA) }\end{array}$ & 11970 & $2836(23.70)$ & 2836 (100) & $2836(100)$ & $65 \pm 12$ & 1434 & $31 \pm 6$ \\
\hline $\begin{array}{l}\text { Rosenfeld et al }{ }^{3} \\
\text { (USA) }\end{array}$ & 28151 & $108(0.38)$ & NA & $66(61)$ & $64 \pm 16$ & 56 & NA \\
\hline $\begin{array}{l}\text { Weingarten et al }{ }^{4} \\
\text { (USA) }\end{array}$ & 164809 & $413(0.25)$ & $413(100)$ & $413(100)$ & $61 \pm 16$ & 221 & $28 \pm 7$ \\
\hline Total n (\%) & 841424 & $4194(0.5)$ & $3333(0.4)$ & $3567(0.42)$ & $58 \pm 6$ & 2210 & $28.8 \pm 3$ \\
\hline
\end{tabular}

BMI, body mass index; n, number; NA, not applicable; OIRD, opioid-induced respiratory depression.

review of included studies is given in the tabular column in online supplementary file S3. The definitions of OIRD varied across studies (online supplementary file S4). These studies were comprised 841424 surgical patients, out of which 4194 patients $(0.5 \%)$ developed postoperative OIRD, with an incidence of 5.0 cases per 1000 anaesthetics delivered (95\% CI: 4.83 to 5.14 ). Among postoperative OIRD events, $80 \%$ (3333/4194) occurred within first 12 hours and $85 \%(3567 / 4194)$ within first 24 hours (table 1). Mean age $e^{4-111314}$ and BMI ${ }^{4-911} 13$ of patients with OIRD was $58 \pm 6$ years and $28.8 \pm 3 \mathrm{~kg} / \mathrm{m}^{2}$, respectively (table 1 ). The quality of studies was scored according to the Newcastle-Ottawa Scale scoring system. The study quality scores varied from 5 to 9 (online supplementary file S5 and S6).

Five studies provided data on OIRD and control groups for inclusion in the meta-analysis. These studies were assessed for potential associations between variable risk factors and postoperative OIRD. ${ }^{45814}$ Figures 2 and 3 summarise the meta-analyses of potential risk factors categorised into demographic risk factors, medical comorbidities, types of surgical procedures, opioid-related risk factors and LOS.

\section{Demographic risk factors}

There was no significant difference between OIRD versus control group in terms of age, gender, BMI and ASA physical status (figure 2). In five studies with data on age, the mean age in OIRD and control group was similar (OIRD vs control; $64 \pm 1$ years vs $61 \pm 2$ years). ${ }^{457814}$ Approximately $50 \%$ of patients in the OIRD group and approximately $56 \%$ of patients in control group were of female gender. ${ }^{457814}$ The mean BMI was $29.6 \pm 1.8 \mathrm{~kg} / \mathrm{m}^{2}$ in OIRD vs $22.9 \pm 12.7 \mathrm{~kg} / \mathrm{m}^{2}$ in control group. ${ }^{478}$ Nearly $69 \%$ and $31 \%$ of patients were ASA I-II and ASA $\geq$ III respectively, in the OIRD group. ${ }^{478}$

\section{Comorbidities}

In 3706 patients with postoperative OIRD, the prevalence of cardiac disease was $45 \%,{ }^{811} \mathrm{DM} 23 \%,{ }^{811}{ }^{14}$ respiratory disease $17 \%,{ }^{581114}$ OSA $18 \%^{4-8} 11-14$ and renal disease $17 \%,{ }^{511} 14$ respectively (online supplementary file S7). Among patients with respiratory disease, $81 \%$ had chronic obstructive pulmonary disease..$^{5811} 14$ We revealed that patients with cardiac disease (OIRD vs control: $42.8 \%$ vs $29.6 \%$; OR: 1.79 ; $95 \%$ CI: 1.2 to 2.5 ; I²: $0 \% ; \mathrm{p}<0.002)^{58}$ and pulmonary disease (OIRD vs control: $17.85 \%$ vs $10.36 \%$; OR: 2.27 ; $95 \%$ CI: 1.3 to 3.6 ; $\mathrm{I}^{2}: 0 \%$; 


$\begin{array}{llll}\text { Trials Risk factor' }^{12}(\%) & \begin{array}{c}\text { OIRD } \\ \text { Group }\end{array} & \begin{array}{c}\text { Control } \\ \text { Group }\end{array} & \text { Pooled estimate OR(95\% Cl) }\end{array}$

Demographic risk factor

${ }^{5} \mathrm{Age}^{84}$

${ }^{5}{ }^{5}$ emale ${ }^{86}$

${ }^{3} \mathrm{BM} \mathbf{1}^{87}$

${ }^{2}$ ASA I \& $\|^{191}$

$2245 / 3249$

$7197 / 9960$

${ }^{2} \mathrm{ASA}>11 \mathrm{II}^{84}$

$2245 / 3249$

7197/9960

$0.93(0.72,1.19)$

$-0.40(-1.23,0.43)$

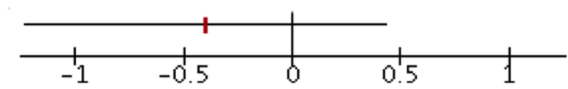

$0.97(0.69,1.36)$

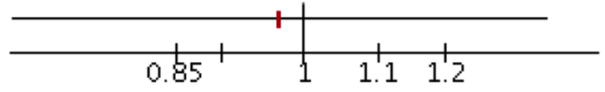

Medical Comorbidities

${ }^{2} C_{\text {ardiac Disease }}{ }^{\circ}$

$84 / 196$

98/330

${ }^{3}$ Pulmonary Disease ${ }^{0}$

$45 / 252$

$40 / 386$

$2.27(1.39,3.70)$

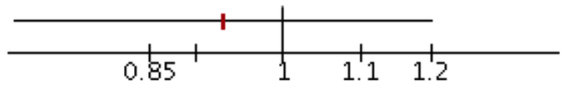

$1.79(1.23,2.60)$

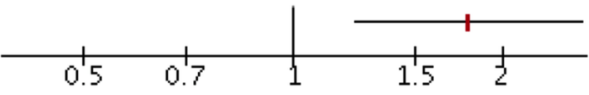

${ }^{5} \mathrm{OSA}^{31}$

$511 / 2735$

942/5779

$1.49(1.19,1.87)$

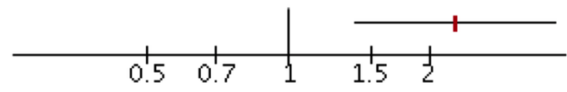

${ }^{2}$ Diabetes Mellitus ${ }^{0}$

$46 / 190$

$57 / 324$

$1.50(0.96,2.34)$

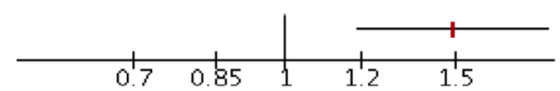

${ }^{2}$ Renal Disease ${ }^{0}$

23/118

$16 / 118$

$1.54(0.77,3.10)$

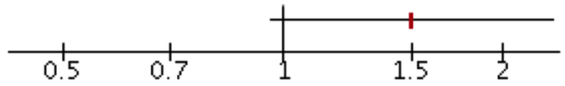

Figure 2 Meta-analysis evaluating the risk factors for respiratory events between OIRD and control groups in patients undergoing surgery. The pooled OR for each risk factor is plotted along with the $95 \% \mathrm{Cl}$ summarises the effect size using the inverse variance random effects model. Age and BMI represented as mean \pm SD. ASA, American Society of Anesthesiologists; BMI, body mass index; $I^{2}$, heterogeneity; OIRD, opioid-induced respiratory depression; OSA, obstructive sleep apnoea.

$\mathrm{p}<0.001)^{5814}$ were associated with increased risk for postoperative OIRD (figure 2).

Nine studies evaluated OSA as a risk factor for OIRD. $^{4-811-14}$ Out of 3706 OIRD patients, 669 patients had OSA $(18 \%)$. Due to lack of data in the control group, only five studies were combined in the meta-analysis. ${ }^{458} 14$ In these five studies ${ }^{4} 7814$ involving 13847 patients, three studies provided data on multivariate adjusted $\mathrm{OR}^{4} 78$ and two studies on univariate unadjusted $\mathrm{OR}^{5}{ }^{514} \mathrm{OSA}$ was found to be significantly associated with OIRD (OR: 1.4; 95\% CI: 1.2 to $1.7 ; \mathrm{I}^{2}: 31 \% ; \mathrm{p}=0.0003$ ) (figure 2 ). Our analysis showed that one study contributed the maximum heterogeneity. ${ }^{8}$ When recalculated with exclusion of this study, pooled estimate was slightly decreased without affecting the final inference of our results (OR: 1.3 ; 95\% CI: 1.16 to 1.48 ; $\mathrm{I}^{2}$ : $0 \% ; \mathrm{p}<0.0001)$. The symmetrical funnel plot and egger's regression test confirmed the absence of the publication bias.

\section{Surgical risk factors}

The type of surgical procedures were general and transplant $(29 \%),{ }^{3-6} 814$ orthopaedic $(84 \%),{ }^{3-8} 14$ thoracic and vascular $(19 \%),{ }^{3-5} 814$ uro-gynaecological $(15 \%),{ }^{3-5814}$ neurosurgeries $(5 \%)^{34814}$ and head and neck surgeries $(5 \%)^{3-614}$ (online supplementary file S8). Seven studies reported on surgical procedures 
TrialsRisk factor ${ }^{12}(\%)$

OIRD

Group

Control

Group

Surgical risk factor

${ }^{3}$ General \& Tranlsplants ${ }^{0}$

$171 / 609$

$316 / 1156$

$1.0(0.8,1.25)$

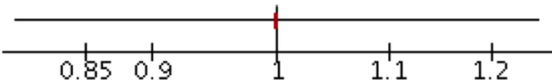

${ }^{3}$ Orthopaedics $^{0}$

$167 / 609$

$312 / 1156$

$1.0(0.8,1.25)$

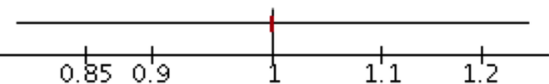

${ }^{3}$ Thoracic \& Vascular ${ }^{0}$

$126 / 609$

247/1156

$1.0(0.78,1.28)$

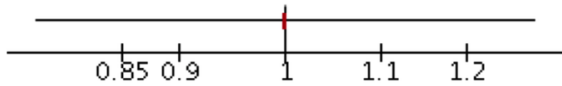

${ }^{2}$ Head \& Neck ${ }^{0}$

$25 / 475$

$48 / 888$

$1.0(0.61,1.64)$

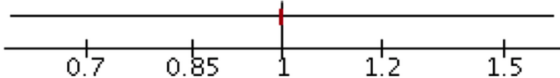

${ }^{2}$ Neurological ${ }^{0}$

$25 / 547$

50/1094

$1.0(0.61,1.64)$

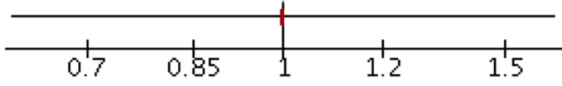

${ }^{3}$ Uro-Gynecological ${ }^{0}$

$94 / 609$

$182 / 1156$

$1.0(0.76,1.64)$

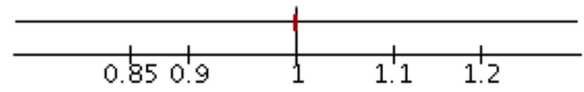

Opioid related risk factor

${ }^{4}$ MEDD Dose $e^{98}$

$24 \pm 14 / 3439$

$18 \pm 13 / 10284$

$2.87(2.03,3.71)$

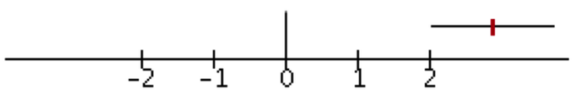

${ }^{2} \mathrm{PCA}^{69}$

$37 / 118$

$40 / 118$

$0.9(0.34,2.38)$

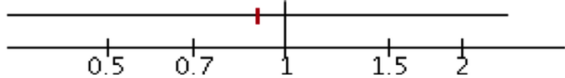

${ }^{2}$ Epidural ${ }^{16}$

$19 / 118$

25/118

$0.71(0.34,1.48)$

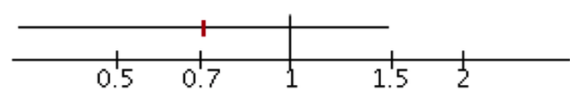

${ }^{3}$ Concomitant Sedation ${ }^{60}$

$367 / 603$

$721 / 1150$

${ }^{3} \operatorname{LOS}^{91}$

$8.8 \pm 2.7 / 531$

$7.7 \pm 2.3 / 944$

$1.26(-0.06,2.58)$

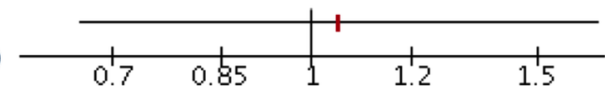

Figure 3 Meta-analysis evaluating the risk factors for respiratory events between OIRD and control groups in patients undergoing surgery. The pooled OR for each risk factor is plotted along with the $95 \% \mathrm{Cl}$ summarises the effect size using the inverse variance random effects model. $I^{2}$, heterogeneity; LOS, length of hospital stay represented as mean $\pm S D ; M E D D$, morphine equivalent daily dose; OIRD, opioid-induced respiratory depression; PCA, patient-controlled analgesia.

involving 3617 patients with OIRD, ${ }^{3-8} 14$ with 3039 $(84 \%)$ being orthopaedic surgery. No differences in surgical categories were detected between OIRD and control group (figure 2).

\section{Opioid-related risk factor}

Four studies reported data on dosage of opioids in OIRD and control group. ${ }^{4814}$ The MEDD of postoperative opioids was higher in OIRD than control (OIRD vs control: $24.7 \pm 14 \mathrm{mg}$ and $18.9 \pm 13.0 \mathrm{mg}$; mean difference: 2.8; $95 \%$ CI: 0.4 to 5.3 ; $\mathrm{I}^{2}: 98 \%$; $\mathrm{p}=0.02$ ) (figure 3 ). In six studies, $57 \%(231 / 402)$ of patients with OIRD received PCA. ${ }^{35} 5101214$ Nearly $40 \%$ of OIRD patients had background continuous infusion of intravenous opioids in addition to PCA. ${ }^{5} 1012$ In four studies, $18.8 \%$ (60/318) of patients with OIRD received epidural opioids. ${ }^{351014}$ Five studies involved 329 patients with OIRD, where nearly $32 \%$ received the analgesia either by oral or intravenous route. ${ }^{3561014}$ Approximately 56\% (399/703) of patients with OIRD received concomitant sedation in addition to opioids $^{4681014}$ (online supplementary file S9). 


\section{Anaesthesia type and LOS}

Only two studies provided data on anaesthesia type as a risk factor for OIRD. ${ }^{48}$ No significant difference in the incidence of OIRD existed between general anaesthesia and general anaesthesia supplemented by neuraxial analgesia. Three studies provided data on LOS involving 531 patients in OIRD and 944 patients in control. ${ }^{4} 514$ The mean difference in LOS was 1.26 days longer in OIRD versus control without any statistical significance (OIRD vs control: $8.84 \pm 2.75$ vs $7.79 \pm 2.31$ days; $\mathrm{MD}: 1.26 ; 95 \% \mathrm{CI}$ : -0.06 to $2.58 ; \mathrm{p}<0.06$ ) (figure 3 ).

\section{DISCUSSION}

To date, this is the first SRMA which evaluated the risk factors associated with OIRD in surgical patients. The incidence of postoperative OIRD in our study population was 5.0 cases per 1000 anaesthetics delivered, where $85 \%$ of cases occurred within the first 24 hours. We identified three patient risk factors: coexisting cardiac disease (1.79fold), pulmonary disease (2.27-fold) and OSA (1.49-fold) that were associated with an increased risk for postoperative OIRD. Patients with OIRD received 23\% higher MEDD than controls.

There was an increased risk of postoperative OIRD in patients who had an underlying cardiac or pulmonary disease. Although the presence of underlying chronic disease is associated with a higher rate of postoperative complications, ${ }^{4} 8111418$ the potential mechanisms for these associations are not clear. These diseases could be markers of overall poor health and diminished cardiorespiratory functional reserve, resulting in a decreased ability to tolerate postoperative opioid analgesics. Alternatively, these diseases themselves may increase patient sensitivity to opioids, thereby increasing the risk for complications.

Recently, Ramachandran et al reported that the presence of cardiac or respiratory disease was independently associated with increased risk of postoperative respiratory complications. ${ }^{19}$ Weingarten et al reported that $34 \%$ patients with postoperative OIRD had pre-existing cardiac disease and $25 \%$ had pre-existing pulmonary disease. ${ }^{8}$ In a US health plan claims database, the presence of cardiopulmonary diseases is included in the screening risk index for serious prescription OIRD or overdose. ${ }^{20} \mathrm{We}$ need to develop a screening risk index to quantify the risk of postoperative OIRD.

Our SRMA indicated that OSA was associated with 1.4-fold higher odds of OIRD compared with control group. OSA remains undiagnosed in many surgical patients. ${ }^{21}$ High risk of OSA (STOP-Bang $\geq 3$ ) was associated with 3.75-fold risk of perioperative complications. ${ }^{22}$ In a meta-analysis of patients with OSA undergoing cardiac surgery, postoperative tracheal intubation and mechanical ventilation was significantly higher in OSA than patients with non-OSA. ${ }^{23} \mathrm{Up}$ to $50 \%$ of surgical patients who died within first 24 hours due to critical respiratory events had OSA diagnosis. ${ }^{11}$ In a closed claims analysis,
OSA or suspected OSA was present in $24 \%$ of patients with postoperative OIRD. ${ }^{10}$

OSA has many endotypes and phenotypes. ${ }^{24}$ In patients with OSA, opioids attenuate the arousal response to hypoxia and prolongs airway obstruction. ${ }^{25}{ }^{26}$ The physiological phenotype of OSA with a high arousal threshold may be more sensitive to the sedative effects of opioids and anaesthetic drugs. ${ }^{25}$ This subgroup has a higher risk of developing OIRD, hypoxaemia and adverse respiratory events, as they depend on arousal for adequate airway and oxygenation. ${ }^{24-26}$ The Society of Anesthesia and Sleep Medicine Guidelines recommend that an institutional protocol for patients with known or suspected OSA should be developed, including type of anaesthesia, choice of medications, postoperative analgesic regimens, monitoring and appropriate perioperative referral in order to reduce complications and ensure best possible patient outcome. $^{27}$

An excessive dose of opioids was administered in 16\% of insurance claims of postoperative OIRD. ${ }^{10}$ Weingarten et al highlighted that the administration of higher doses of intraoperative opioids (MEDD 40 mg (29-50 mg), $\mathrm{p}<0.001)$ was significantly associated with a higher incidence of OIRD, with a 22\% higher risk of OIRD with every $10 \mathrm{mg}$ intravenous MEDD. ${ }^{4}$ The mean MEDD opioid dose in patients who died due to respiratory-related critical event had been shown to be $0.55 \mathrm{mg} / \mathrm{kg} /$ day (range: $0.26-0.88 \mathrm{mg} / \mathrm{kg} /$ day) and increased sensitivity to opioids may play a role in OIRD. ${ }^{11}$

Subramani et al reported that some surgical patients with death or near-death events received a low opioid dose of MEDD $<10 \mathrm{mg} /$ day. ${ }^{28}$ Further analysis of the dosage of intravenous opioids found a clear doseresponse pattern with increased odds of death/neardeath with increasing dose of opioids (ORs of 1.0, 1.5 and 3.0 at opioid doses of $<10 \mathrm{mg}, 10-25 \mathrm{mg}$ and $>25 \mathrm{mg}$; p for trend $<0.005) .{ }^{28}$ Chung et al reported that 72 hours total opioid dose is a predictive factor for postoperative sleep-disordered breathing. ${ }^{29}$ A significant increase in central sleep apnoea occurred in patients on high doses of opioids (MEDD $>200 \mathrm{mg}$ /day) for chronic pain. ${ }^{26}$ With higher doses of opioids, the increase in sleep-disordered breathing can be an important contributor to OIRD.

Use of PCA for analgesia may lead to administration of a higher total dose of opioids, thus enhancing the risk of OIRD. ${ }^{30}$ A continuous background infusion of opioids compounds the risk of OIRD, especially 8-24 hours after start of the infusion as the effect-site concentration of opioids and their metabolites reach their peak at this time. $^{30} 31$ Continuous background infusion of opioids should be avoided while using PCA as there is no pharmacokinetic advantage of PCA morphine together with a background opioid infusion. ${ }^{31}$

In this review, concomitant administration of sedatives and opioids was revealed in $56 \%$ of patients with OIRD. A propensity-matched analysis of the effects of preoperative gabapentin to patients undergoing laparoscopic surgery found that gabapentin was associated with an increased 
rate of OIRD postoperatively. ${ }^{32}$ The continuation of home gabapentin/pregabalin into the postoperative period was strongly associated with a sixfold increase in OIRD in surgical wards. ${ }^{33}$ In closed claims analysis, coadministration of sedatives and opioids occurred in $34 \%$ of postoperative OIRD. ${ }^{10}$

In a retrospective analysis of inpatient discharges, Overdyk et al reported a 3.5-fold increased risk of cardiopulmonary arrest in patients who were administered sedatives together with opioids compared with only a 1.8 times increased risk with either sedatives or opioids alone. ${ }^{34}$ In a study of veterans who died due to opioid overdose, coadministration of benzodiazepines and opioids increased the risk of mortality fourfold..$^{35}$ Concomitant administration of sedatives and opioids is an avoidable risk factor. In a multimodal analgesic regimen, decreasing the dose of opioids when gabapentins is administered may minimise the risk of OIRD. ${ }^{32}$ Education of healthcare providers and patients regarding the risk of opioids and sedatives is the key to decrease risk of OIRD.

Our meta-analysis showed that the majority of OIRD is reported within the first 12 hours and 24 hours accounting for $80 \%$ and $85 \%$ OIRD, respectively. Similar to our results, $88 \%$ of insurance claims were related to postoperative OIRD within 24 hours. ${ }^{10}$ Two other studies highlighted that around $60 \%$ of postoperative critical respiratory events occurred within 12 hours postoperatively. ${ }^{5}$ The highest risk period for OIRD is the first 6-hour postsurgical period ${ }^{48}$ with $34 \%$ of the critical respiratory events. ${ }^{11}$ This is probably due to a combination of the residual effects of anaesthetic medications. It has been suggested that prolonging the Post Anesthesia Care Unit (PACU) stay in patients with high-risk of OIRD may decrease the incidence of critical respiratory events, as a result of more intensive monitoring and earlier intervention. ${ }^{36}$ Enhanced monitoring during this period in the vulnerable patients will mitigate OIRD. ${ }^{29} 3738$ The sample size and number of studies included in each of these risk factors varied as the authors of the various studies did not examine the same risk factors to evaluate the postoperative OIRD. Some of the studies in this review found a significant association between postoperative OIRD and age $>50$ years, ${ }^{5}{ }^{12} \mathrm{BMI}^{4}$ and ASA 3 or $4,{ }^{4}$ but the pooled estimate did not find any significant association with age, gender, BMI or ASA physical status.

To prevent OIRD, the use of sedatives like benzodiazepines and gabapentin together with opioids should be minimised. Age, BMI, gender and comorbidities of patients should be considered while administering opioids. Continuous background infusion of opioids should be avoided while using PCA. Multimodal analgesia and an opioid sparing strategy with use of non-opioid analgesics will decrease risk of OIRD. ${ }^{39}$

In the postoperative period, enhanced monitoring of levels of sedation and ventilation (respiratory rate (RR), pulse oximetry and capnography) especially in patients with high-risk of OIRD such as cardiopulmonary diseases, and OSA will enable us to detect OIRD and intervene earlier. ${ }^{3940}$ Although the majority of studies in this SRMA were conducted in USA, the results are quite generalisable, as these studies are conducted from different institutions involving different population at different time period.

This meta-analysis has the limitations inherent to observational studies, as the quality and completeness of medical and nursing records would have adversely influenced the study results. Naloxone administration was used to measure OIRD in $75 \%$ of studies. ${ }^{458-111314}$ As mild cases of OIRD may not be reported, the true incidence of OIRD would have been underestimated, leading to a measurement bias. Typically, OIRD is defined using two classes of criteria: (1) 'threshold criteria', where OIRD is a deviation of RR, pulse oxymetry value or arterial carbon dioxide tension from an arbitrary threshold and (2) 'rescue criteria' using indirect evidence of OIRD, such as the use of an opioid or sedative reversal drug, positive pressure ventilation or a documented respiratory arrest. Such 'rescue criteria' interventions are sensitive, but non-specific markers for OIRD, and occur less frequently than events meeting threshold criteria. Naloxone administration is the only treatment currently available to reverse OIRD, and all our studies included in the meta-analysis used the naloxone as the rescue criteria.

In addition to these limitations, some of the risk factors evaluated in our study had the high heterogeneity. However, the thresholds for the interpretation of $\mathrm{I}^{2}$ can be misleading, since the importance of inconsistency depends on several factors. ${ }^{41}$ In our meta-analysis, heterogeneity was expected as the studies had the considerable variation as they were conducted at different time periods, in different population and different centres. Further, the lack of uniformity in the data prevented us to perform the meta-regression analysis and explore the heterogeneity. Finally, publication bias cannot be ruled out as our inclusion criteria included only the articles published in English language.

In conclusion, the incidence of postoperative OIRD was $0.5 \%$ and $85 \%$ which occurred within the first 24 hours. Increased risk for OIRD was associated with pre-existing cardiac disease, pulmonary disease and OSA. The administration of higher doses of opioids is associated with an elevated risk of OIRD. These findings should be used to develop strategies for enhanced monitoring of high-risk surgical patients requiring opioid analgesia to prevent OIRD.

\section{Author affiliations}

${ }^{1}$ Department of Anesthesia and Pain Management, Toronto Western Hospital, University Health Network, University of Toronto, Toronto, Ontario, Canada

${ }^{2}$ Department of Anesthesia and Perioperative Medicine, London Health Sciences Centre and St. Joseph Health Care, Western University, London, Ontario, Canada ${ }^{3}$ Department of Anesthesia and Pain Management, University Health Network, University of Toronto, Toronto, Ontario, Canada

${ }^{4}$ Institute of Health Policy, Management and Evaluation, University of Toronto THETA Collaborative, Toronto General Research Institute, Toronto, Ontario, Canada

${ }^{5}$ Department of Anesthesia and Perioperative Medicine, Mayo Clinic Rochester, Rochester, Minnesota, USA 
Acknowledgements The authors thank Marina Englesakis, Information Specialist, Surgical Divisions, Neuroscience \& Medical Education, Health Sciences Library, University Health Network, Toronto, Ontario, Canada, for her assistance with the literature search.

Contributors KG, MN, FC: designed the study, conducted the study, analysed the data and wrote the manuscript. AP: helped to design the study and wrote the manuscript. LA, TNW: helped with interpretation of data and manuscript writing. JW: helped with manuscript writing.

Funding The authors have not declared a specific grant for this research from any funding agency in the public, commercial or not-for-profit sectors.

Competing interests JW reports grants from the Ontario Ministry of Health and Long-Term Care, Anesthesia Patient Safety Foundation and Acacia Pharma outside of the submitted work. FC reports research support from the Ontario Ministry of Health and Long-Term Care, University Health Network Foundation, Acacia Pharma, Medtronic grants to institution outside of the submitted work, up-to-date royalties, STOP-Bang proprietary to University Health Network. TNW currently serves as a consultant to Medtronic in the role as chairman of the Clinical Endpoint Committee for the Prodigy Trial; has received unrestricted investigator-initiated grants from Merck (active) and Baxter (completed), and research support from Respiratory Motion (study equipment) and research support from Respiratory Motion (study equipment).

Patient consent Not required.

Provenance and peer review Not commissioned; externally peer reviewed.

Data sharing statement No additional data available.

Open access This is an open access article distributed in accordance with the Creative Commons Attribution Non Commercial (CC BY-NC 4.0) license, which permits others to distribute, remix, adapt, build upon this work non-commercially, and license their derivative works on different terms, provided the original work is properly cited, appropriate credit is given, any changes made indicated, and the use is non-commercial. See: http://creativecommons.org/licenses/by-nc/4.0/.

\section{REFERENCES}

1. Frasco PE, Sprung J, Trentman TL. The impact of the joint commission for accreditation of healthcare organizations pain initiative on perioperative opiate consumption and recovery room length of stay. Anesth Analg 2005;100:162-8.

2. Kessler ER, Shah M, Gruschkus SK, et al. Cost and quality implications of opioid-based postsurgical pain control using administrative claims data from a large health system: opioid-related adverse events and their impact on clinical and economic outcomes. Pharmacotherapy 2013;33:383-91.

3. Rosenfeld DM, Betcher JA, Shah RA, et al. Findings of a naloxone database and its utilization to improve safety and education in a tertiary care medical center. Pain Pract 2016;16:327-33.

4. Weingarten TN, Chong EY, Schroeder DR, et al. Predictors and outcomes following naloxone administration during Phase I anesthesia recovery. J Anesth 2016;30:116-22.

5. Taylor S, Kirton OC, Staff I, et al. Postoperative day one: a high risk period for respiratory events. Am J Surg 2005;190:752-6.

6. Etches RC. Respiratory depression associated with patientcontrolled analgesia: a review of eight cases. Can $J$ Anaesth 1994;41:125-32.

7. Weingarten TN, Jacob AK, Njathi CW, et al. Multimodal analgesic protocol and postanesthesia respiratory depression during phase i recovery after total joint arthroplasty. Reg Anesth Pain Med 2015;40:330-6.

8. Weingarten TN, Herasevich V, McGlinch MC, et al. Predictors of delayed postoperative respiratory depression assessed from naloxone administration. Anesth Analg 2015;121:422-9.

9. Khelemsky Y, Kothari R, Campbell N, et al. Incidence and demographics of post-operative naloxone administration: a 13-year experience at a major tertiary teaching institution. Pain Physician 2015;18:E827-9.

10. Lee LA, Caplan RA, Stephens LS, et al. Postoperative opioid-induced respiratory depression: a closed claims analysis. Anesthesiology 2015;122:659-65.

11. Ramachandran SK, Haider N, Saran KA, et al. Life-threatening critical respiratory events: a retrospective study of postoperative patients found unresponsive during analgesic therapy. J Clin Anesth 2011;23:207-13.

12. Overdyk FJ, Carter R, Maddox RR, et al. Continuous oximetry/ capnometry monitoring reveals frequent desaturation and bradypnea during patient-controlled analgesia. Anesth Analg 2007;105:412-8.
13. Shapiro A, Zohar E, Zaslansky R, et al. The frequency and timing of respiratory depression in 1524 postoperative patients treated with systemic or neuraxial morphine. J Clin Anesth 2005;17:537-42.

14. Gordon DB, Pellino TA. Incidence and characteristics of naloxone use in postoperative pain management: a critical examination of naloxone use as a potential quality measure. Pain Manag Nurs 2005;6:30-6.

15. Moher D, Liberati A, Tetzlaff J, et al. Preferred reporting items for systematic reviews and meta-analyses: the PRISMA statement. Ann Intern Med 2009;151:264-9.

16. Wells GSB, O'Connell D, Peterson J, et al. The Newcastle-Ottawa Scale (NOS) for assessing the quality if nonrandomized studies in meta-analyses Ottawa. 2014 http//www.ohri.ca/programs/clinical_ epidemiology/oxford.asp.

17. Stroup DF, Berlin JA, Morton SC, et al. Meta-analysis of observational studies in epidemiology: a proposal for reporting. Meta-analysis Of Observational Studies in Epidemiology (MOOSE) group. JAMA 2000;283:2008-12.

18. Morris TA, Gay PC, Maclntyre NR, et al. Respiratory compromise as a new paradigm for the care of vulnerable hospitalized patients. Respir Care 2017;62:497-512.

19. Ramachandran SK, Pandit J, Devine S, et al. Postoperative respiratory complications in patients at risk for obstructive sleep apnea: a single-institution cohort study. Anesth Analg 2017;125:272-9.

20. Zedler BK, Saunders WB, Joyce AR, et al. Validation of a screening risk index for serious prescription opioid-induced respiratory depression or overdose in a US commercial health plan claims database. Pain Med 2018;19:68-78.

21. Singh M, Liao P, Kobah S, et al. Proportion of surgical patients with undiagnosed obstructive sleep apnoea. $\mathrm{Br} J$ Anaesth 2013;110:629-36.

22. Nagappa M, Patra J, Wong J, et al. Association of STOP-bang questionnaire as a screening tool for sleep apnea and postoperative complications: a systematic review and bayesian meta-analysis of prospective and retrospective cohort studies. Anesth Analg 2017:125:1301-8.

23. Nagappa M, Ho G, Patra J, et al. Postoperative outcomes in obstructive sleep apnea patients undergoing cardiac surgery: a systematic review and meta-analysis of comparative studies. Anesth Analg 2017;125:2030-7.

24. Subramani $Y$, Singh M, Wong J, et al. Understanding phenotypes of obstructive sleep apnea. Anesthesia \& Analgesia 2017;124:179-91.

25. Lam KK, Kunder S, Wong J, et al. Obstructive sleep apnea, pain, and opioids: is the riddle solved? Curr Opin Anaesthesiol 2016;29:134-40.

26. Correa D, Farney RJ, Chung F, et al. Chronic opioid use and central sleep apnea: a review of the prevalence, mechanisms, and perioperative considerations. Anesth Analg 2015;120:1273-85.

27. Chung F, Memtsoudis SG, Ramachandran SK, et al. Society of anesthesia and sleep medicine guidelines on preoperative screening and assessment of adult patients with obstructive sleep apnea. Anesth Analg 2016;123:452-73.

28. Subramani $Y$, Nagappa $M$, Wong J, et al. Death or near-death in patients with obstructive sleep apnoea: a compendium of case reports of critical complications. Br J Anaesth 2017;119:885-99.

29. Chung $\mathrm{F}$, Liao $\mathrm{P}$, Elsaid $\mathrm{H}$, et al. Factors associated with postoperative exacerbation of sleep-disordered breathing Anesthesiology 2014;120:299-311.

30. Blake DW, Yew CY, Donnan GB, et al. Postoperative analgesia and respiratory events in patients with symptoms of obstructive sleep apnoea. Anaesth Intensive Care 2009;37:720-5.

31. George JA, Lin EE, Hanna MN, et al. The effect of intravenous opioid patient-controlled analgesia with and without background infusion on respiratory depression: a meta-analysis. J Opioid Manag 2010;6:47-54.

32. Cavalcante AN, Sprung J, Schroeder DR, et al. Multimodal analgesic therapy with gabapentin and its association with postoperative respiratory depression. Anesth Analg 2017;125:141-6.

33. Deljou A, Hedrick SJ, Portner ER, et al. Pattern of perioperative gabapentinoid use and risk for postoperative naloxone administration. Br J Anaesth 2018;120:798-806.

34. Overdyk FJ, Dowling O, Marino J, et al. Association of opioids and sedatives with increased risk of in-hospital cardiopulmonary arrest from an administrative database. PLoS One 2016;11:11:e0150214.

35. Park TW, Saitz R, Ganoczy D, et al. Benzodiazepine prescribing patterns and deaths from drug overdose among US veterans receiving opioid analgesics: case-cohort study. BMJ 2015;350:h2698. 
36. Weingarten TN, Warner LL, Sprung J. Timing of postoperative respiratory emergencies: when do they really occur? Curr Opin Anaesthesiol 2017;30:156-62.

37. Chung F, Liao P, Yang Y, et al. Postoperative sleep-disordered breathing in patients without preoperative sleep apnea. Anesth Analg 2015;120:1214-24.

38. Chung F, Liao P, Yegneswaran B, et al. Postoperative changes in sleep-disordered breathing and sleep architecture in patients with obstructive sleep apnea. Anesthesiology 2014;120:287-98.
39. Horlocker TT, Burton AW, Connis RT, et al. Practice guidelines for the prevention, detection, and management of respiratory depression associated with neuraxial opioid administration. Anesthesiology 2009;110:218-30.

40. Khanna AK, Khanna AK, Khanna AK. Respiratory depression on the wards: why better monitoring may be the answer? Anesthesiology Open Journal 2017;2:9-11.

41. Borenstein M, Higgins JP, Hedges LV, et al. Basics of meta-analysis: $\mathrm{I}^{2}$ is not an absolute measure of heterogeneity. Res Synth Methods 2017;8:5-18. 